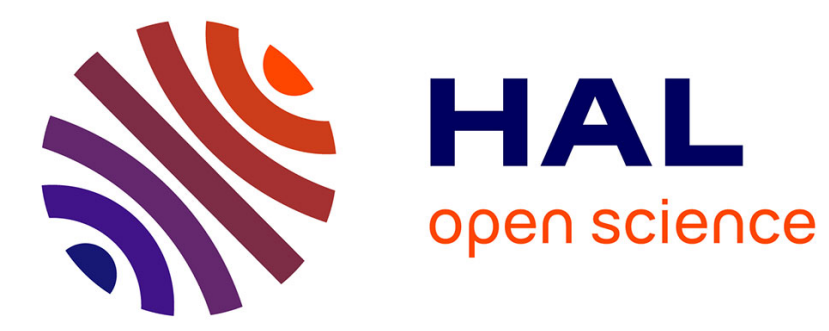

\title{
Multi-scale stochastic morphological models for 3D complex microstructures
}

Maxime Moreaud, Johan Chaniot, Thierry Fournel, Jean Marie Becker, Loïc Sorbier

\section{- To cite this version:}

Maxime Moreaud, Johan Chaniot, Thierry Fournel, Jean Marie Becker, Loïc Sorbier. Multi-scale stochastic morphological models for 3D complex microstructures. 2018 17th Workshop on Information Optics (WIO), Jul 2018, Québec, Canada. pp.1-3, 10.1109/WIO.2018.8643455 . hal-02095021

\section{HAL Id: hal-02095021 https: / hal-ifp.archives-ouvertes.fr/hal-02095021}

Submitted on 10 Apr 2019

HAL is a multi-disciplinary open access archive for the deposit and dissemination of scientific research documents, whether they are published or not. The documents may come from teaching and research institutions in France or abroad, or from public or private research centers.
L'archive ouverte pluridisciplinaire HAL, est destinée au dépôt et à la diffusion de documents scientifiques de niveau recherche, publiés ou non, émanant des établissements d'enseignement et de recherche français ou étrangers, des laboratoires publics ou privés. 


\title{
Multi-scale stochastic morphological models for 3D complex microstructures
}

\author{
Maxime Moreaud $^{1}$, Johan Chaniot ${ }^{1}$, Thierry Fournel ${ }^{2}$, Jean Marie Becker ${ }^{2}$ and Loïc Sorbier ${ }^{1}$
}

\begin{abstract}
The analysis of 3D images of complex materials, once imaging and reconstruction steps have been thoroughly done, can provide essential information. This analysis can be largely enhanced by using a modeling of the observed media, based on a reduced set of interpretable parameters. Besides, a common feature to many materials as diverse as concrete, rocks, bones, nanomaterials or heterogeneous catalysts is a multi-scale morphology with the meaning that specific morphological features exist at various length scales. Access to these different length scales' information is essential in order to understand and modelize these materials. This is a central point in the optimization of the usage properties of these materials such as mechanical strength or mass transport, which need a preliminary characterization of their morphology with the help of an adequate model. We propose here a modelization based on the so-called multi-scale Boolean models, models which have been successfully related to some usage properties, of primary importance for the design of new microstructures. These models are based on a reduced set of parameters related to interpretable material manufacturing settings. We illustrate the use of these models for the following tasks: representation of real multi-scale material like alumina catalyst supports, estimation of critical percolation threshold and assessment of tortuosity and accessibility. In addition, their efficient computing and visualization are addressed using "plug im!", a signal and image processing modular open access software.
\end{abstract}

\section{INTRODUCTION}

The materials considered here are biphasic in a very special sense, the two phases being presence/absence of matter. Mechanical properties, diffusion properties and other usage properties depend on the ratio of material / vacuum intrinsic properties and on its microstructure. The usage properties of these materials are modified by changing the constituents or by modifying their microstructure. Concerning this second point, it is necessary to be able to model it and to propose realistic changes, if possible in connection with manufacturing processes. Random morphological models allow it [1]; they rely on a random placement of grains in space and on random grains' shapes. Boolean model is especially interesting [2]. Complex microstructure arrangements can be obtained by combining a certain number of levels of this elementary model. This will be illustrated on nanocomposite materials based on nanoparticles of alumina, ceramic materials that can be used as catalysts support [3].

\footnotetext{
${ }^{1}$ M. Moreaud, J. Chaniot and L. Sorbier are with IFP Energies nouvelles, Rond-point de l'échangeur de Solaize, BP 3, 69390 Solaize, France maxime.moreaude ifpen. fr

${ }^{2}$ T. Fournel and J.M. Becker are with Université de Lyon, Université Jean Monnet de Saint Etienne, CNRS UMR 5516, Laboratoire Hubert Curien, F-42000 Saint Etienne, France
}

\section{MODELIZATION OF MULTI-SCALE 3D MICROSTRUCTURES}

\section{A. Boolean model}

A Poisson Point process [4] follows two properties. First, number $N$ of points to be placed follows a Poisson distribution of parameter $\theta$. This parameter depends on the average volume $(\bar{V})$ of the primary grains of the material $\left(A^{\prime}\right)$ and the volume fraction $\left(V_{v}\right)$ occupied by them:

$$
1-V_{v}=\exp \left(-\theta \bar{V}\left(A^{\prime}\right)\right)
$$

Then, $N$ points are created following a uniform distribution of their coordinates. Finally, a Boolean model $A$ is obtained by implantation of random primary grains $A^{\prime}$, with possible overlapping, on Poissonian points $x_{k}$ with intensity $\theta$.

$$
A=\bigcup_{x_{k}} A_{x_{k}}^{\prime}
$$

Modifying the volume fraction of grains, their size and shape gives a wide range of modelization possibilities fitting, rather well, as we will see, with materials and their manufacturing processes.

\section{B. Union and intersection of Boolean models}

The raw Boolean model we have just described is not sufficient for the description of multi-scale microstructures. We need for that to use two-scale simulations corresponding to the intersection of two Boolean schemes [5]. In this way, it is possible to model an aggregated grains arrangement in inclusion zones modeled by one of the two models. Grains outside these aggregates can be accounted for by taking the union of another Boolean model with the previous one.

Other even more complex microstructures can be characterized by exclusion zones free of any grain. It is possible to model them using a three-scale model, taking the intersection with the complementary of a Boolean model in addition to the previous models. We summarize these different types of increasingly complex microstructures in Table I.

Unfortunately, these models generate some unrealistic microstructure features ; in particular, the grains are cut due to intersection binary operations, a phenomenon that is not present in real microstructures.

\section{More realistic microstructures}

Realistic microstructures can be modeled by using a slightly different process. If we think in terms of seeds where the grains are to be implanted (Poisson process), we differ this implantation until the end of the models' intersections ; in this way the grains' shapes are preserved (cf. Fig. 1). This 


\begin{tabular}{|c|c|}
\hline Uniform distribution & $A_{0}$ \\
\hline Aggregates only & $A_{0} \cap A_{1}$ \\
\hline Aggregates & $\left(A_{0} \cap A_{1}\right) \cup A_{2}$ \\
\hline Aggregates and strong porosity & $\left(\left(A_{0} \cap A_{1}\right) \cup A_{2}\right) \cap A_{3}^{c}$ \\
\hline
\end{tabular}

TABLE I: Increasingly complex microstructures are obtained by combining different Boolean models.

type of model uses Cox point processes [6]. The intersection of two models is done in the following way : only the grains of the first model whose seeds fall inside the second model are preserved. The model associations detailed in the previous section remain the same (cf. Fig. 2). More details can be found in [7]. These models can also be used in a very simple way using "plug im!" open access software [8].
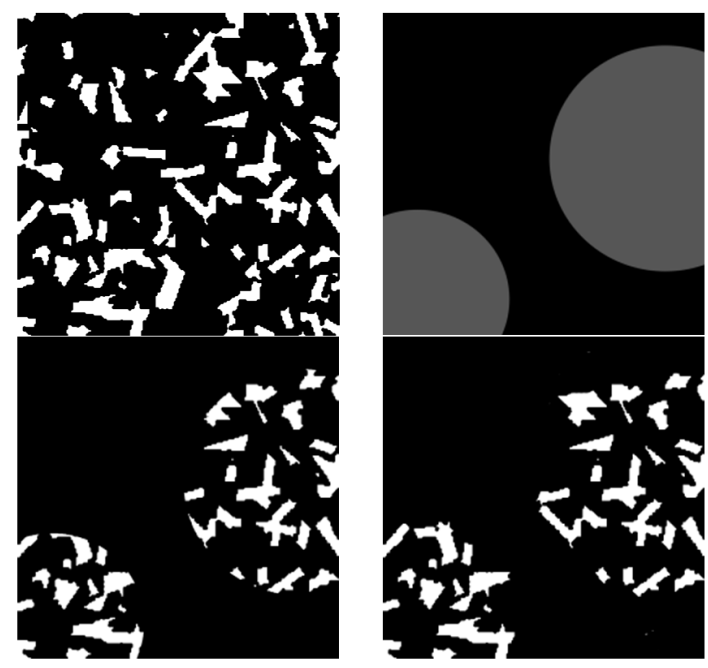

Fig. 1: First line : Boolean model of platelets and Boolean model of spheres denoting aggregate scale. Second line : intersection of the two Boolean models, by standard operation or using Cox point process which provides a more realistic microstructure.

\section{ILLUSTRATION AND TOPOLOGICAL CHARACTERIZATION}

These complex models can be used to model several microstructures of materials. Some examples : nanofibers microstructure [9], carbon black nanocomposites [10] (cf. Fig. 3) or even alumina nanoplatelets microstructures [3]. For nanofibers and carbon black microstructures, one scale Boolean model is used, with spherocylinders and spheres with radius following exponential law respectively.

In [9], these models are used to estimate critical percolation thresholds. A particular algorithm for building multiscale models [7] using the infinite divisibility property of a Boolean model, can drastically reduce the number of object collision tests necessary for the estimation of percolation thresholds. These models have been used also to estimate effective dielectric properties in [7].

For alumina nanoplatelets microstructure, the model is more

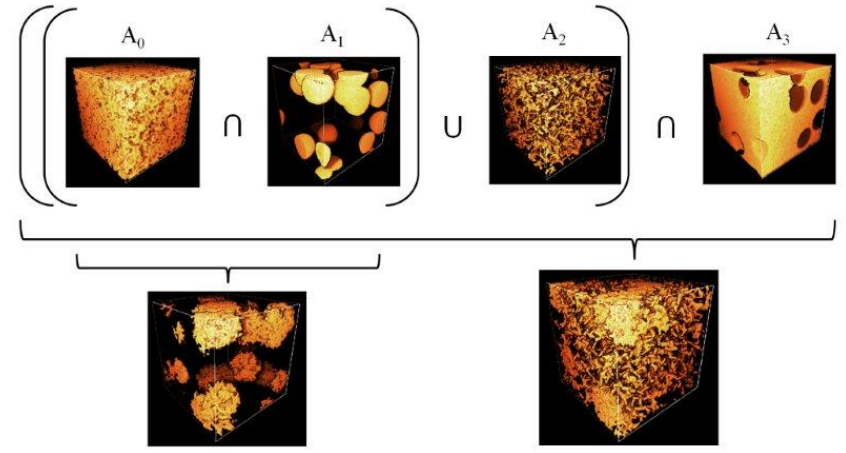

Fig. 2: Illustration of combination of Boolean models as in Table I and using Cox point process.

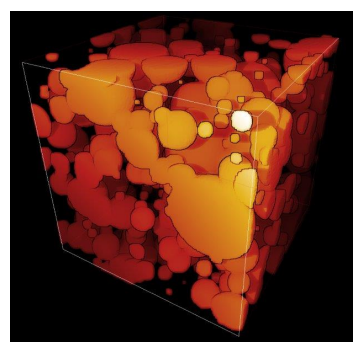

(a)

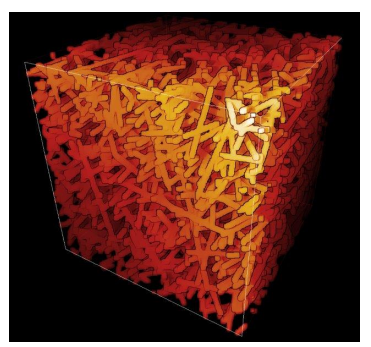

(b)
Fig. 3: Illustrations of carbon blacks nanocomposites and nanofibers microstructures. Volumes rendered by "plug im!" [8].

complex : a first Boolean model of spheres defines the size of aggregates and two Boolean models of platelets with different densities and orientation laws define platelets outside and inside aggregates.

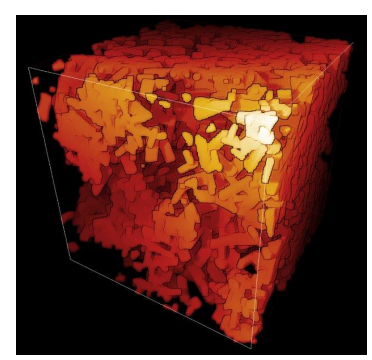

Fig. 4: Illustration of alumina nanoplatelets microstructure. Volumes rendered by "plug im!" [8].

In [11], these models have been used to estimate nanoplatelets average size, and also to simulate realistic numerical Transmission Electron Microscopy (TEM) images (cf. Fig. 5). In [13], these models have been used to compute adsorption and desorption isotherms by numerical simulation and to predict pore size distribution associated to porosimetry. They have also been used in [12] to simulate mass transport by hindered diffusion. Using these models, several topological features can also be calculated. In [14], 

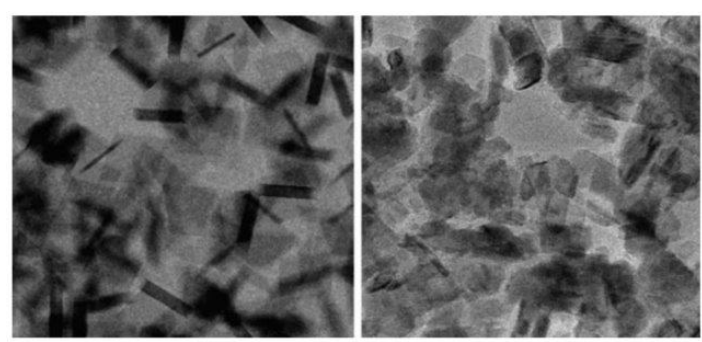

Fig. 5: TEM image simulation using morphological random model (left: simulation; right: experimental image. from [11]).

the accessible porous volume is given according to a probe molecule size. This approach also makes it possible to define a critical radius, i.e. a maximum diameter of the molecule being able to pass entirely through the porous volume of a microstructure. A geometric tortuosity parameter can also be defined and used to characterize the more or less easy way to cross the porous network. A stochastic approach, proposed in [15], gives global information even in the case of complex microstructures. This descriptor will be accessible in "plug im!" [8].

\section{CONCLUSIONS}

Boolean models make it possible to model microstructures with a complex arrangement, while keeping a relatively concise and easily transferable parameterization to realistic manufacturing process parameters. This means, for instance, quantity and shape of primary grains or aggregates of grains. This can be achieved by combining several Boolean models ; this can be done very easily through "plug im!" software [8]. Numerous examples of these multi-scale models can be found in the literature, modeling microstructures of complex materials as diverse as nanocomposites based on carbon black or fibers, or nanomaterials based on nanoparticles of alumina. It is then interesting to characterize the topological aspects of these microstructures, in particular considering accessibility of the porous network. These are characteristics of primary interest for these materials used as catalysts or as particles' filter.

\section{REFERENCES}

[1] G. Matheron, "Random sets and integral geometry", J. Wiley, New York, 1975.

[2] J. Serra, "Image Analysis and Mathematical Morphology", Academic Press London, 1982.

[3] H. Wang, A. Pietrasanta, D. Jeulin, F. Willot, M. Faessel, L. Sorbier, M. Moreaud ,"Modelling mesoporous alumina microstructure with 3D random models of platelets", Journal of Microscopy, vol. 260, no 3, pp. 287-301, 2015.

[4] J.F.C. Kingman, "Poisson Processes", Oxford Science Publications, Oxford Studies in Probability 3, 1993.

[5] L. Savary, D. Jeulin, A. Thorel, "Morphological analysis of carbonpolymer composite materials from thick sections", Acta Stereologica, vol. 18 , no 3, pp. 297-303, 1999.

[6] D. Jeulin, "Advances in Theory and Applications of Random Sets", World Scientific, Fontainebleau, 1996.

[7] M. Moreaud, "Propriétés morphologiques multi-échelles et prévision du comportement diélectrique de nanocomposites", M. Moreaud, Thèse Ecole des Mines de Paris, 2006.
[8] "plug im!" an open access and customizable software for signal and image processing. https://www.plugim.fr

[9] D. Jeulin, M. Moreaud, "Percolation of random cylinder aggregates", Image Analysis and Stereology, vol. 26, pp.121-127, 2007.

[10] D. Jeulin, M. Moreaud, "Multi-scale simulation of random spheres aggregates application to nanocomposites", 9th European Congress on Stereology and Image Analysis, Zakopane, Poland, vol. I, pp. 341-348, May 10-13 2005.

[11] M. Moreaud, D. Jeulin, V. Morard, R. Revel, "TEM image analysis and modelling: application to boehmite nanoparticles", Journal of Microscopy vol. 245, no 2, pp. 186-199, 2012.

[12] H. Wang, F. Willot, M. Moreaud, M. Rivallan, L. Sorbier, D. Jeulin, "Numerical simulation of hindered diffusion in $\gamma$-alumina supports", Oil\&Gas Science and Technology, vol. 72, no 2, 8, 2017.

[13] H. Wang, D. Jeulin, F. Willot, L. Sorbier, M. Moreaud, "Modelling of the microstructure of mesoporous alumina constrained by morphological simulation of nitrogen porosimetry", Colloids and Surfaces A: Physicochemical and Engineering Aspects, Elsevier, vol. 553, pp. 378396, 2018

[14] J. Chaniot, M. Moreaud, T. Fournel, J.M. Becker, "The reachable volume fraction in porous media in the vicinity of percolation threshold: a numerical approach used on multi-scale Boolean schemes", 16th Workshop on Information Optics, 2017.

[15] J. Chaniot, M. Moreaud, T. Fournel, J.M. Becker, "Tortuosimetric operator for Complex Porous Media Characterization", Stereology, Spatial Statistics and Stochastic Geometry, Prague, Czech Republic, June 25th, 2018, unpublished. 